\title{
First report of rust caused by Puccinia oxalidis on Oxalis debilis in India
}

\author{
Nitika Bansal ${ }^{1} \cdot$ Ratnaboli Bose $^{1} \cdot$ Amit Pandey $^{1} \cdot$ Maneesh S. Bhandari ${ }^{2} \cdot$ Shailesh Pandey ${ }^{1}$ (I)
}

Received: 29 June 2021 / Accepted: 15 November 2021 / Published online: 25 November 2021

(c) Società Italiana di Patologia Vegetale (S.I.Pa.V.) 2021

Keywords Oxalis debilis $\cdot$ Puccinia oxalidis $\cdot$ Rust $\cdot$ New host

Oxalis debilis, an ethnomedicinally important plant, grows naturally in Uttarakhand, India. In March 2021, typical rust pustules were observed on $O$. debilis in a reserve forest area of Forest Research Institute, Dehradun. Disease incidence was $100 \%$ and the infected plants withered and died. Uredinia were powdery, mostly growing on the undersurface of leaves, occasionally found on the stem, erumpent, and dark yellow-orange in color. Urediniospores were yelloworange, subglobose to ellipsoidal, echinulate, and measured $15.26-20.17 \times 13.15-16.58 \mu \mathrm{m}$ (mean $17.83 \times 14.96 \mu \mathrm{m})$ $(n=20)$. Teliospores were not observed. Based on the host species and morphological characters, the rust fungus was identified as Puccinia oxalidis. DNA was extracted from the urediniospores using phenol-chloroform method. The internal transcribed spacer (ITS) and larger subunit (LSU) regions were amplified using primer pairs ITS 5 / ITS 4 and LROR / LR5, respectively. PCR products were sequenced by Biokart India Pvt. Ltd., Bengaluru. A BLASTn search with the ITS sequence (MZ442316) revealed $>99 \%$ homology with $P$. oxalidis from China (MW522517) and India (MK640668). Likewise, the closest match (>99\% homology) of the LSU region (MZ425499) was with P. oxalidis from Korea (MH325474, MH325473) and USA (KY798348). Phylogenetic analysis of the individual ITS and LSU sequences conducted using the MOLE-BLAST tool (https://blast.ncbi.nlm.nih.gov/moleblast/moleblast.cgi) and concatenated data set using maximum parsimony method, further confirmed the species as $P$. oxalidis. Five $O$. debilis plants, when inoculated by rubbing a piece of infected leaf on the abaxial side of healthy leaves, developed typical rust

Shailesh Pandey

pandeysh@icfre.org; shailesh31712@yahoo.co.in

1 Forest Pathology Discipline, Forest Protection Division, Forest Research Institute, Dehradun, India

2 Genetics and Tree Improvement Division, Forest Research Institute, Dehradun, India symptoms 15 days post inoculation in a glasshouse at $25^{\circ} \mathrm{C}$ and $90 \%$ relative humidity. The symptoms and morphology of the uredinospores were similar to those observed on the naturally infected plants. No symptoms developed on control plants, which were mock-inoculated by rubbing with healthy leaves. Recently, $P$. oxalidis reported for the first time on O. debilis var. corymbosa in Korea (Lee et al. 2019). In India, four Oxalis species. (O. corniculata, O. corymbosa, O. dehradunensis and $O$. latifolia) are well-known host for $P$. oxalidis (Farr and Rossman 2021; Verma et al. 2020). However, to our knowledge, this is the first report of $P$. oxalidis inciting rust on $O$. debilis in India and is an important addition to the molecular taxonomy of an Indian rust.

Supplementary information The online version contains supplementary material available at https://doi.org/10.1007/s42161-021-01013-x.

Funding Authors are thankful to the Indian Council of Forestry Research and Education, Dehradun, Uttarakhand for financial support.

\section{Declarations}

Conflict of interest The authors declare no conflict of interest.

\section{References}

Farr DF, Rossman AY (2021) Fungal Databases, U.S. National Fungus Collections, ARS, USDA. https://nt.ars-grin.gov/fungaldatabases/

Lee SH, Lee CK, Cho SE, Shin HD (2019) First report of rust caused by Puccinia oxalidis on Oxalis debilis var. corymbosa in Korea. Plant Dis 103: 148 https://doi.org/10.1094/PDIS-05-18-0777-PDN

Verma RK, Gautam AK, Singh A, Avasthi S, Prasher IB, Nautiyal MC, Singh H (2020) New record of rust disease caused by Puccinia oxalidis on Oxalis latifolia from India. MycoAsia - Journal of Modern Mycology 1-12

Publisher's Note Springer Nature remains neutral with regard to jurisdictional claims in published maps and institutional affiliations. 